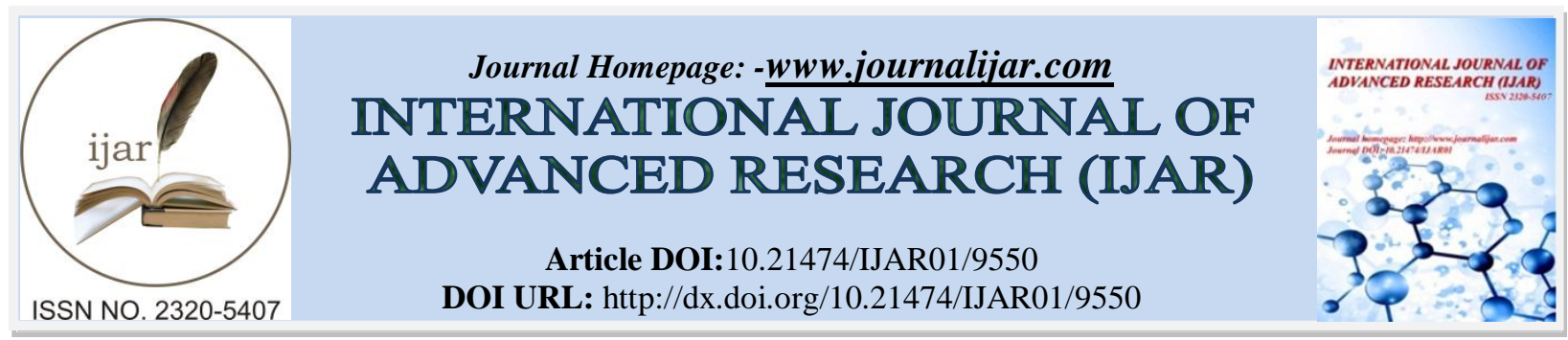

RESEARCH ARTICLE

\title{
MULTITRAIT PGPRS AS POTENTIAL INOCULANTS FOR COTTON PLANT.
}

Twisha M. Patel ${ }^{1}$, Farida P. Minocheherhomji ${ }^{2}$.

1. Research Scholar, Microbiology Department, B. P. Baria Science Institute, Navsari, Gujarat, India.

2. Associate Professor, Microbiology Department, B. P. Baria Science Institute, Navsari, Gujarat, India.

\section{Manuscript Info}

Manuscript History

Received: 08 June 2019

Final Accepted: 10 July 2019

Published: August 2019

Key words:-

Bio-inoculants ; PGPR ; Vigour index.

\begin{abstract}
In soil, plant growth depends on many biotic and abiotic factors. The plant rhizosphere supports large and active microbial population because of root exudation. These naturally occurring root bacteria are beneficial for plant growth vizdirectly and indirectly known as plant growth promoting rhizobacteria (PGPR). Our study includes isolation and screening of rhizobacteria from nonrhizospheirc and rhizospheric soil of cotton plant. We have found total 60 isolates. These isolates were tested in vitro for specific PGPR traits such as nutrient solubilzation (Phosphorus, Potassium), and different biocontrol activity tests (Antifungal activity, Ammonia production, $\mathrm{HCN}$ production, Siderophores Production). Out of all, four isolates (Bacillus cereus, Ensiferglycinis,

Stenotrophomonasrhizophila, Staphylococcushaemolyticus) were found to be promising for most of plant growth promoting traits. These PGPR were used as bioinoculant for cotton seeds and not for control sample. The seeds inoculation with PGPRs affected germination rate and seedling vigour index. The higher germination rate (75\%) and seedling vigour index (825) were obtained with PGPRs treated seeds where as in control it was $56.25 \%$ and 506.25 respectively. Results suggest that combination of multitraits PGPRs can be considered as alternative biofertilizer and biopesticide to promote cotton seed germination, crop yield and act as an alternative to chemical fertilizer.
\end{abstract}

Copy Right, IJAR, 2019,. All rights reserved.

\section{Introduction:-}

The excessive use of agrochemicals fertilizers and pesticides is causing harmful effects to soil fertility and soil fauna and flora (Yu et al., 2009). So, during the last couple of decades, numerous recent biotechnological expansions in agriculture have been discovered and as a result new area for the increase of the crop productivity in a sustainable environment arises (Tank and Saraf , 2010). Microorganisms associated with plant as mutualistic partner has an adaptation to the environment and have the capacity to support the plant for the growth and crop yield. Therefore rhizobacteria now developed as biofertilizers or biopesticides to increase soil fertility and control plant disease.

Plant growth is generally supported directly and indirectly by PGPR. The direct mechanisms include facilitating resource acquisition (Nitrogen, Phosphorus, Potassium, zinc and essential minerals), ACC deaminase activity and modulating plant hormone levels (Auxin, cytokinine, giberellic acid, ethylene, abscisic acid). Indirect mechanisms

Corresponding Author:-Mrs. Twisha M. Patel.

Address:-Research Scholar, Microbiology Department, B. P. Baria Science Institute, Navsari, Gujarat, India. 
include decrease of the inhibitory effects of various pathogens on plant growth and development in the forms of biocontrol agents, such as HCN, siderophore, lytic enzyme production and antifungal activity (Glick,1995).

So keeping all these in views, our objectives were focused to isolate, identified PGPR, screening of their plant growth promoting traits [PGP] and evaluatemultitrait PGPRs from rhizospheric soil of cotton plant. These PGPRs were necessary for improving agricultural crops yield which act as biofertilizers, phytostimulators and biocontrol for sustaining the agro-ecosystems.

\section{Material and methods:-}

Sample collection:

Samples for PGPR study were collected from Agriculture Farm, Cotton Research Centre, Surat, Gujarat. Soil consisting mainly of two zone nonrhizospheric (Bulk soil) along with three different site from rhizospheric (rhizosphere, rhizoplane and endorhizosphere) of Gossypiumhisrsutum (cotton) was selected for study.

\section{Isolation of PGPR :}

Bacterial species were isolated from the nonrhizospheric soil and rhizospheric soil samples using various appropriate selective media such as Pikovskaya agar, Nitrogen free media, Ashby's Mannitol agar, King's media, Bacillus media, Yeast Extract Mannitol Agar. Plates were incubated at room temperature until visible growth was observed.

In Vitro screening of plant growth promoting traits (PGP) of rhizobacteria (PGPR) :

The bacteria were screened for 6 different plant growth promoting traits. Rhizobacteria directly or indirectly promotes plant growth activities and their multifunctional traits were tested. They were screened for 2 nutrient solubilizing traits and 4 different biocontrol activity tests.

\section{Nutrient solubilizing traits:}

Phosphate solubilisation:

Rhizobacteria were screened for phosphate solubilization on Pikovskaya medium (Gupta et al., 1994).

\section{Potassium solubilisation:}

Potassium solubilization by rhizobacteria was studied on Aleksandrov medium plates (Liu et al., 2012).

\section{Biocontrol activity:}

Antagonism assay against phytopathogenic fungi:

Isolates were assayed for antifungal activities against Fusarium species using Potato Dextrose Agar (PDA) medium (Manivannan,2012).

\section{Ammonia production:}

Bacterial isolates were tested for the production of $\mathrm{NH}_{3}$ in peptone water (Cappuccino and Sherman,1992).

Hydrogen cyanide production:

Screening of rhizobacteria for $\mathrm{HCN}$ production werestreaked on nutrient agar medium containing $4.4 \mathrm{~g} / \mathrm{l}$ of glycine (Castric 1975).

\section{Siderophore production:}

Siderophore production was tested qualitativelty using Chrome azurol S (CAS) agar (Schwyn and Neilands, 1987).

\section{Construction of PGPR consortia:}

The four different rhizobacteria that demonstrated as good plant growth promoting traits were chosen to construct consortia for improvement of plant health and defense mechanism.

\section{Molecular Characterizations and phylogenetic study :}

Microbial Identification was done with the use of $16 \mathrm{~S}$ rDNA according tomultitraits PGPR on the basis of quantitative analysis. DNA was isolated from the bacterial culture. Its quality was evaluated on 1.0\% Agarose Gel, a single band of high-molecular weight DNA has been observed. Fragment of 16S rDNA gene was amplified by PCR. A single discrete PCR amplicon band was observed when resolved on Agarose. The PCR amplicon was purified by column purification to remove contaminants. DNA sequencing reaction of PCR amplicon was carried out with $8 \mathrm{~F}$ 
\&1492R primers using BDT v3.1 Cycle sequencing kit on ABI 3730xl Genetic Analyzer. The 16S rDNA sequence was used to carry out BLAST with the database of NCBI genbank database. Based on maximum identity score first ten sequences were selected and aligned using multiple alignment software programs and their phylogenetic relationships determined.

\section{Multitraits consortium involved in plant growth and Development In Vitro seed germination assay}

The bacterial strains were bio assayed for their ability to promote seed germination and growth of cotton seedlings using standard methods. The seeds were surface sterilized with $0.1 \% \mathrm{HgCl}_{2}$ for 3 min. followed by successive washing with sterile distilled water twice and then the water was decanted. The seeds were then added to followed set cultures grown in their respective medium for $48 \mathrm{hr}$., kept for 10 minutes in the consortium culture and the medium was decanted. After the treatments, inoculated seeds were arranged in an equidistant manner in a sterile Petri dish previously wallpapered with cotton moistened with $10 \mathrm{ml}$ of sterile distilled water. The Petri dish was closed and incubated incubated at $30{ }^{\circ} \mathrm{C}$ for 2-7 days. The seeds treated with sterilized medium alone were used as control. After germination, the number of germinated seeds per Petri dish was counted in order to determine the germination percentage (Shende, 1977). The root and shoot lengths of each germinated seed were measured to determine the vigour index (Abdul-Baki, 1973).

\section{Greenhouse studies:}

A pot culture study was undertaken with the above treatments by using Completely Randomized Design (CRD) The used soil was sterilized twice at $120^{\circ} \mathrm{C}$ for $20 \mathrm{~min}$ with 24 hours times' interval (Gholami, 2009). Pots were filled with soil. A $5 \mathrm{~cm}$ deep hole was opened in the centre of each pot. Treated cotton seeds with multitraitspgpr consortium were sown in each pot. Control (soil + untreated seeds) was also included. Sixty Days after Sowing, growth parameter were determined according to the procedures described by Newman (1966), Mollaet al. (2001) and Cassanet al. (2009).

\section{Plant growth and development parameter: \\ Growth Parameter:}

1. Plant height

2. Flowering and Ball formation and busting stage

3. Percentage germination $($ Germ $\%)=\frac{\text { No of germinated seed }}{2} \times 100$

Total number of seeds cultured .i

4. Vigour index $=\%$ Germination $\mathrm{X}$ seedling length (shoot length + root length)

\section{Ressult and discussion:-}

Bacteria are involved in various biotic activities of the soil ecosystem (Ahemad et al., 2009 and Chandler et al., 2008). They stimulate plant growth through solubilizing nutrients in soils, producing numerous plant growth regulators, protecting plants from phytopathogens by controlling or inhibiting them and improving soil quality (Ahemad, 2012 ; Ahemad and Malik, 2012 ; Hayat et al., 2010 ; Rajkumar et al., 2010 and Braud et al., 2009). Indeed, the bacteria which are present around/in the plant roots (rhizobacteria) are more versatile in transforming, mobilizing, solubilizing the nutrients compared to those from bulk soils (Hayat et al., 2010). Therefore, the rhizobacteria are the dominant driving forces in recycling the soil nutrients and increasing soil fertility (Glick, 2012).

60 bacterial species were isolated from the four different site - bulk soil, rhizosphere, rhizoplane, endorhizosphere of wild and transgenic cotton. They were screened for 6 plant growth promoting traits in Table 1.

\begin{tabular}{|l|l|l|}
\hline \multicolumn{1}{|c|}{ Sr No. } & \multicolumn{1}{|c|}{ PGP traits } & \multicolumn{1}{|c|}{$\begin{array}{c}\text { Number of positive organisms (Total 60 } \\
\text { isolates) }\end{array}$} \\
\hline 1 & Phosphate solubilization & 24 \\
\hline 2 & Potassium solubilization & 10 \\
\hline 3 & Antifungal activity - Fusarium sp. & 06 \\
\hline 4 & Ammonia production & 17 \\
\hline 5 & HCN production & 03 \\
\hline
\end{tabular}




\begin{tabular}{|l|l|l|}
\hline 6 & Siderophore production & 15 \\
\hline
\end{tabular}

Table 1:-Plant growth promoting traits

Plant growth promoting traits do not work independently of each other but multiple mechanisms, such as nutrient solubilization, phytohormone production, various enzyme activity and biocontrol activity are responsible for the plant growth promotion and increased yield (Bashan and Holguin, 1997).The various multitraits PGPR identified using 16S rDNA (Figure 1).

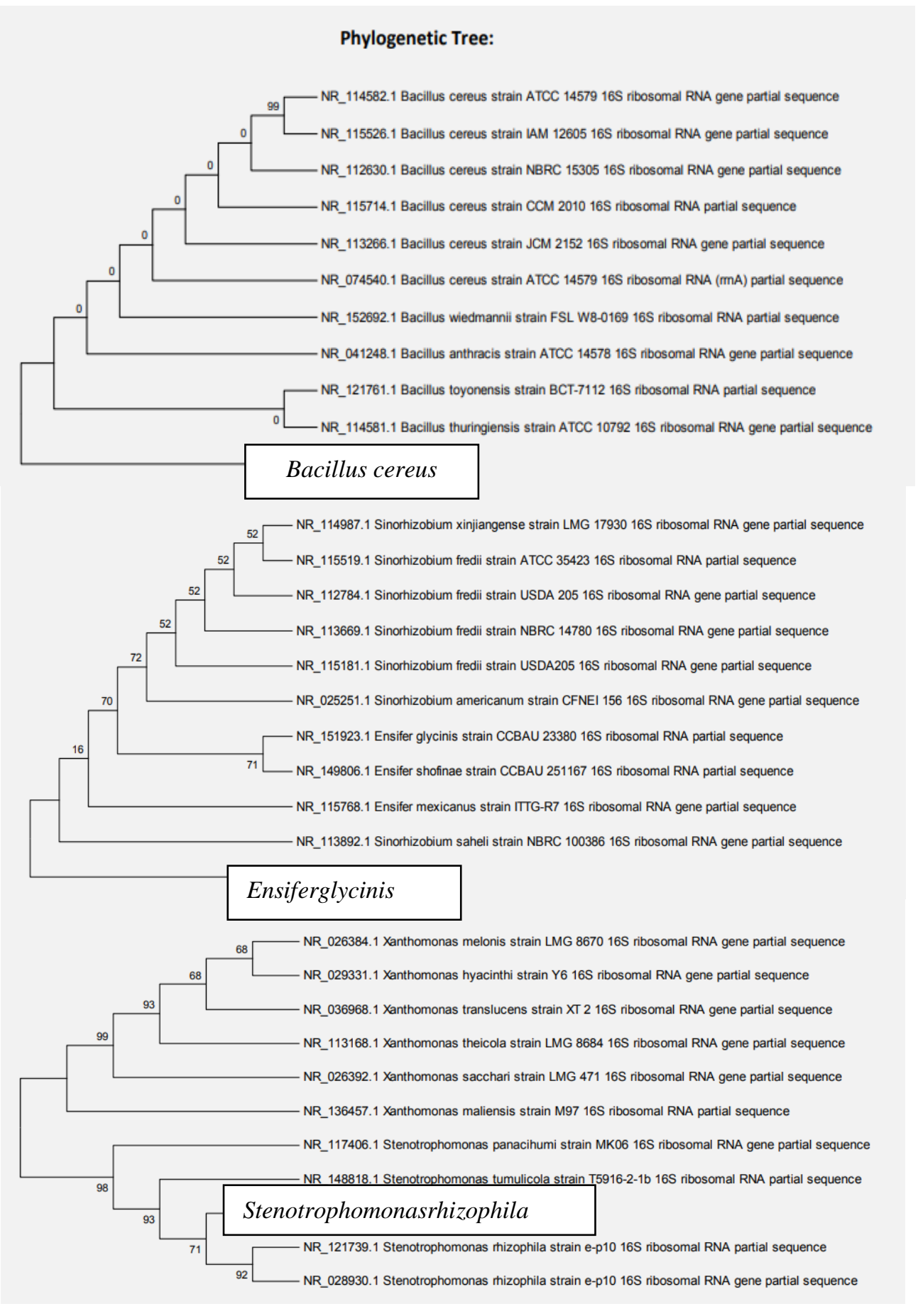




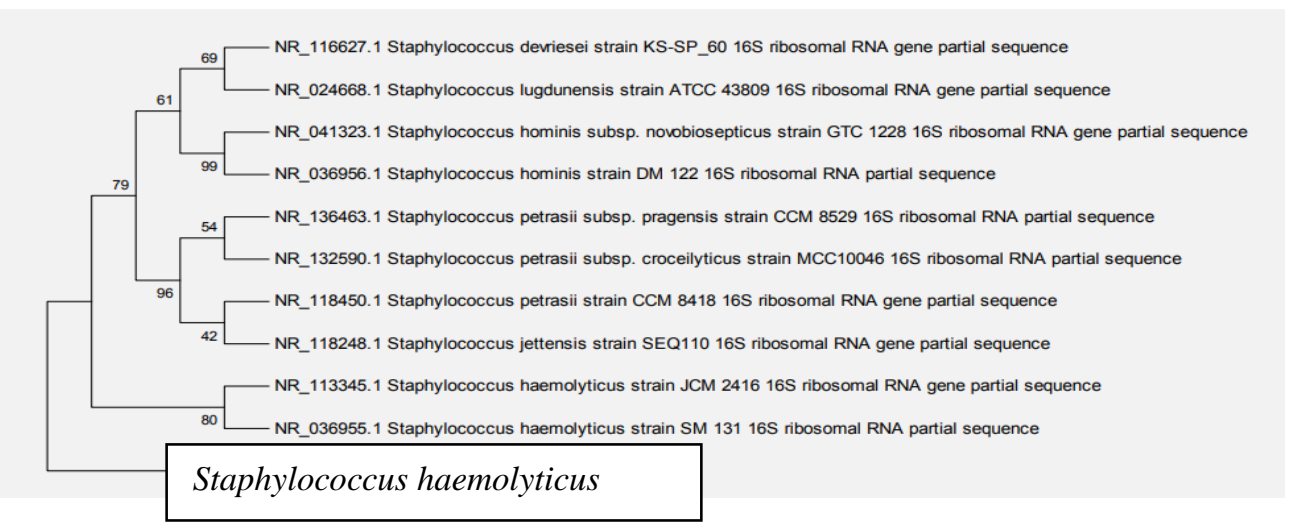

Among all multitraits PGPRs, three PGPRs consortium (Bacillus cereus, Ensiferglycinis, Stenotrophomonasrhizophila, Staphylococcushaemolyticus) were found to be promising for plant growth promoting traits in vitro condition.

Our data revealed that PGPR consortium treatment promotes cotton seed germination in vitro plate assay (Table 2).

\begin{tabular}{|c|c|c|}
\hline & Control seeds & PGPR treated seeds \\
\hline $\begin{array}{l}\text { Total number of } \\
\text { cultured seeds }\end{array}$ & 16 & 16 \\
\hline $\begin{array}{l}\text { Total number of } \\
\text { germinated seeds }\end{array}$ & 9 & 12 \\
\hline $\begin{array}{l}\text { Percentage } \\
\text { germination }\end{array}$ & $56.25 \%$ & $75 \%$ \\
\hline $\begin{array}{l}\text { Root and Shoot } \\
\text { length }\end{array}$ & $\begin{array}{l}7 \mathrm{~cm} \text { shoot } \\
2 \mathrm{~cm} \text { root }\end{array}$ & $\begin{array}{l}9 \mathrm{~cm} \text { shoot } \\
2 \mathrm{~cm} \text { root }\end{array}$ \\
\hline Vigour index & 506.25 & 825 \\
\hline Diagram & & \\
\hline
\end{tabular}

Table 2:-In vitro seed germination plate assay

It revealed that under in vitro conditions, seed treatment with PGPR strains improved seed germination, seedling vigor, seedling emergence and seedling stand over the control. Similar improvement of seed germination parameters by rhizobacteria has been reported in cotton (Baljeet Singh Saharan and Vibha Nehra,2011).In green house study, PGPR also increased cotton development stages, seed cotton yield and plant height over respective controls in following Figure $2 \& 3$. 


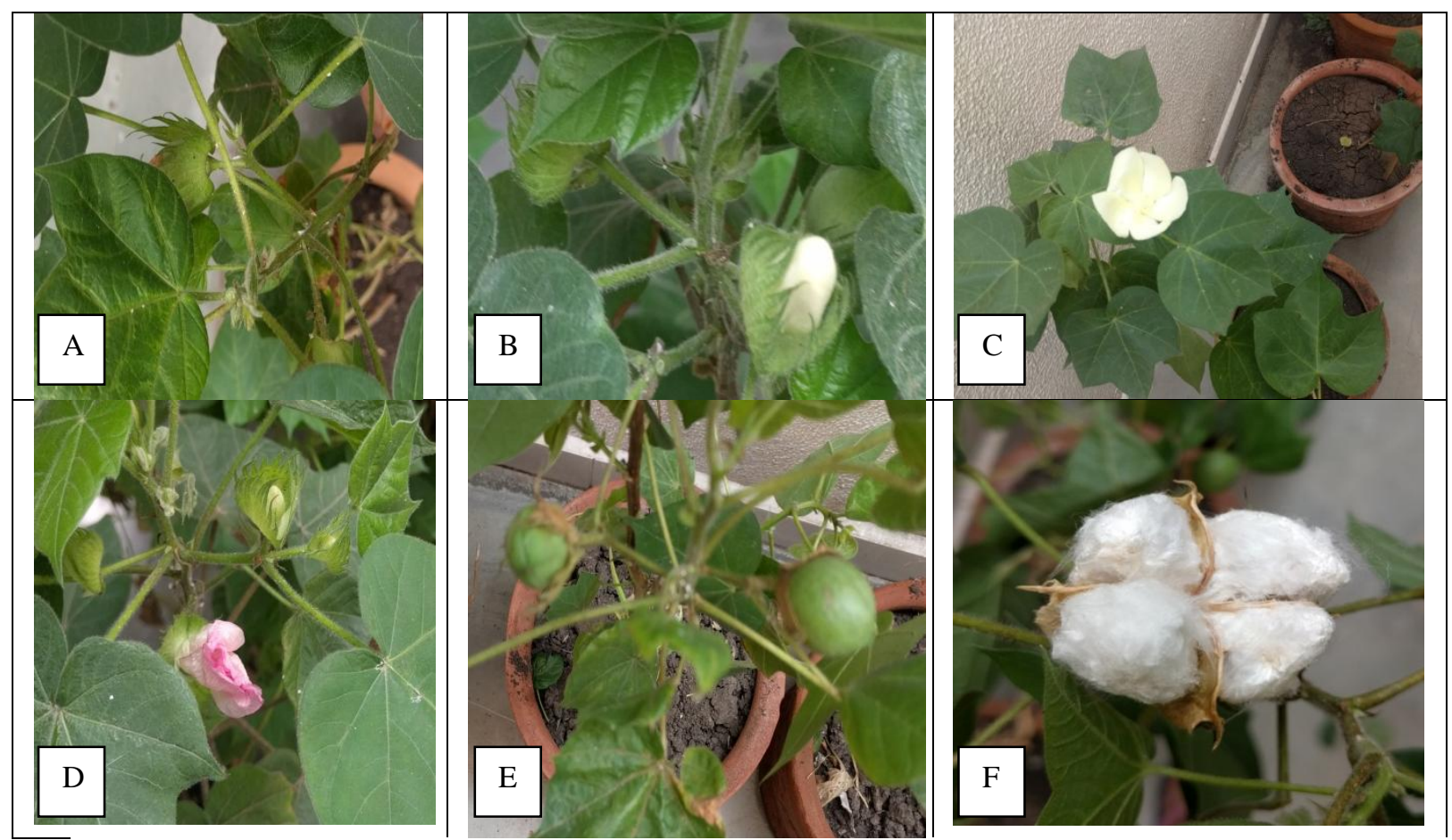

$\mathbf{A}$ :Bud formed, B : Bloom formation, C : Bloom, D : few hours later, white becomes pink , E : Boll matures . F : Cotton

Figure 2 :-Stages of cotton development

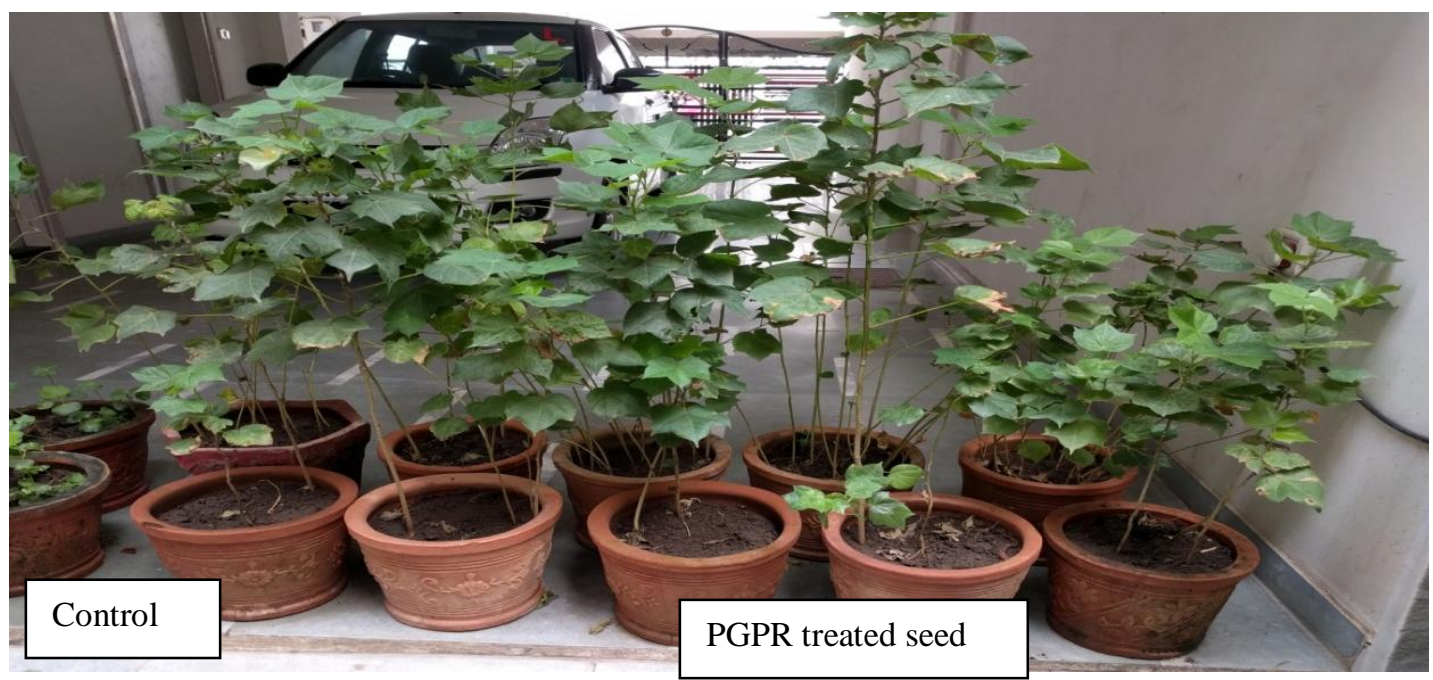

Figure 3:-Green house study

In our present experiment 60 PGPR strains were isolated from cotton rhizosphere, 4 were selected based on their PGP ability, and further study was conducted to know their effect on seed germination, vigour index. Bacillus cereus, Ensiferglycinis, Stenotrophomonasrhizophila, Staphylococcus haemolyticus consortium showed higher PGP traits as well as increase in \% germination as compared to untreated control. Similar enhancement of seed germination in cotton crop was also reported (Anjum et al., 2007). Similar improvement of seed germination parameters by rhizobacteria has been reported in other cereals such as sorghum (Raju et al.,1999) and pearl millet. The improvement in seed germination by PGPR was also found in wheat and sunflower (Niranjanet al., 2003)(Niranjanet al., 2004).

\section{Conclusion:-}


The present study proved that the PGPR strains were effective in making nutrient available to the plant, helped in biological control of plant pathogens and deleterious microbes improving the growth promoting activities such as seed germination and vigour index. Thus our study confirms the effect of PGPR on germination and plant growth. The inoculation of cotton seeds (Gossypiumhirsutum) by the rhizobacteria improved in vitro germination. These results suggest the possibility to use these PGPR further as can be further exploited as biofertilizers, phytostimulator and biopesticides for plant growth promotion which finally restrict the use of chemicalfertilizer in agriculture and to increase the output of cotton.

\section{Acknowledgements:-}

The authors thank the authorities of Agriculture Cotton Research Centre, Surat, for providing samples used in this research.

\section{References:-}

1. Gholami, S. Shahsavani and S. Nezarat, "The Effect of Plant Growth Promoting Rhizobacteria (PGPR) on Germination, Seedling Growth and Yield of Maize," World Academy of Science, Engineering and Technology, Vol. 49, 2009, pp. 19-24.

2. A.A. Abdul-Baki and J.D. Anderson, Vigour determination in soyabeen seed by multiple criteria, Crop Sc., 13(6), 1973, 630-633

3. Ahemad, M. and Khan, M.S. (2009). Effect of insecticide-tolerant and plant growth promoting Mesorhizobium on the performance of chickpea grown in insecticide stressed alluvial soils. J. Crop Sci. Biotechnol., 12: 213-222.

4. Ahemad, M., \& Khan, M. S. (2012). Alleviation of fungicide-induced phytotoxicity in greengram [Vignaradiata(L.) Wilczek] using fungicide-tolerant and plant growth promoting Pseudomonas strain. Saudi journal of biological sciences, 19(4) :451-459.

5. Ahemad, M., \& Malik, A. (2012). Bioaccumulation of heavy metals by zinc resistant bacteria isolated from agricultural soils irrigated with wastewater.

6. Baljeet Singh Saharan and Vibha Nehra, Assessment of plant growth promoting Attributes of cotton (Gossypiumhirsutum) Rhizosphere isolates and their Potential as bio-inoculants, Journal of Environmental Research And Development, 5(3), 2011, 575-583.

7. Bashan, Y. and Holguin, G. (1997). Azospirillum-plant relationships: environmental and physiological advances. Canadian Journal of Microbiology, 43(2): 103-121.

8. Braud, A., Jézéquel, K., Bazot, S., and Lebeau, T. (2009). Enhanced phytoextraction of an agricultural Cr-and $\mathrm{Pb}$-contaminated soil by bioaugmentation with siderophore-producing bacteria. Chemosphere, 74(2) :280-286.

9. Cappuccino, J. C., \& Sherman, N. (1992). Negative staining. Microbiology: A LaboratoryManual, 3: 125-179.

10. Cassan, F., D. Perrig, V. Sgroy, O. Masciarelli, C. Penna and V. Luna, 2009. Azospirillumbrasilense Az39 and BradyrhizobiumjaponicumE109, inoculated singly or in combination, promote seed germination and early seedling growth in corn (Zea mays L.) and soybean (Glycine max L.). Eur. J. Soil. Biol., 45: 28-35.

11. Castric P A (1975), "Hydrogen cyanide, a secondary metabolite of Pseudomonasaerogenous", Can. J. Microbiol., Vol. 21, pp.613-618.

12. Chandler, D., Davidson, G., Grant, W. P., Greaves, J., \& Tatchell, G. M. (2008). Microbial biopesticides for integrated crop management: an assessment of environmental and regulatory sustainability. Trends in Food Science \& Technology, 19(5): 275-283.

13. Glick, B, R. (2012).Plant Growth-Promoting Bacteria: Mechanisms and Applications. Hindawi Publishing Corporation, Scientifica

14. Glick, B.R. (1995). The enhancement of plant growth by free living bacteria. Canadian Journal of Microbiology, 41 (2): 109-114.

15. Gupta, R. S., Rekha, S., Aparna. andKuhad, R. C. (1994). A modified plate assay for screening phosphate solubilizing microorganisms. J. Gen. Appl. Microbiol. 40:255-260.

16. Hayat, R., Ali, S., Amara, U., Khalid, R. and Ahmed, I. (2010). Soil beneficial bacteria and their role in plant growth promotion: a review. Annals of Microbiology, 60(4): 579-598.

17. Liu, D., Lian, B. and Dong, H., (2012). Isolation of Paenibacillussp. and assessment of its potential for enhancing mineral weathering. Geomicrobiology Journal, 29: 413- 421.

18. M.A. Anjum, M.R. Sajjad, N. Akhtar, M.A. Qureshi, A. Iqbal, A.R. Jami and M. Hasan, Response of cotton to Plant Growth Promoting Rhizobacteria (PGPR) inoculation under different levels of nitrogen, J. Agri. Res., 45(2), , 2007,135-143. 
19. Manivannan, M. (2012). Isolation, screening, characterization and antagonism assay of PGPR isolates from rhizosphere of rice plants in CuddaloreDistrict.InternationalJournal of Pharmaceutical \& Biological Archive, $3(1)$.

20. Molla, A.H., M.S. Shamsuddin, M. Morziah and A.B. Puteh, 2001. Potential for enhancement of root growth and noduation of soybean co-inoculated with Azospirillum and Bradyrhizobium in laboratory systems. Soil Biol. Biochem., 33: 457-463.

21. N.S. Raju., S. R. Niranjana., G. R. Janardhana., H. S. Prakash., H. S.Shetty and S.B. Mathur, Improvement of seed quality and field emergence of Fusarium moniliforme infected sorghum seeds using biological agents, J. Sci. Food. Agric., 79, 1999, 206.212.

22. Newman, E.I., 1966. A method for estimating the total length of root in a sample. J. Appl. Ecol., 3: 139-145

23. Rajkumar, M., Ae, N., Prasad, M. N. V. and Freitas, H. (2010). Potential of siderophore-producing bacteria for improving heavy metal phytoextraction. Trends in Biotechnology, 28: 142-149.

24. S.R. Niranjan., N.P. Shetty and H.S. Shetty, Seed bio-priming with Pseudomonas fluorescens isolates enhances growth of pearl millet plants and induces resistance against downy mildew, J.pest.manage., 50(1), 2004, 41-48. 2004

25. S.R. Niranjan., S.A. Deepak., P. Basavaraju., H.S. Shetty., M.S. Reddy and J.W. Kloepper, Comparative performance of formulations of plant growth promoting rhizobacteria in growth promotion and suppression of downy mildew in pearl millet, Crop Protection., 22, 2003, 579-588.

26. S.T. Shende, R.G. Aple, and T. Singh, Influence of Azatobacter on germination of rice and cotton seeds, Curr. Sci. 46, 1977, 675 - 676.

27. Schwyn, R., Neilands, J.B., Anal Biochem, (1987), 160: 47-56.

28. Tank, N. and M. Saraf. (2010). Salinity-resistant plant growth promoting rhizobacteria ameliorates sodium chloride stress on tomato plants. J. Plant Interactions, 5: 51-58.

29. Yu, Y., Chu, X., Pang, G., Xiang, Y. and Fang, H. (2009). Effects of repeated applications of fungicide carbendazim on its persistence and microbial community in soil, J. Environ. Sci., 21:179-185. 